J.L.TOP*, J.N.M. AGRICOLA* and A.F. FORT. Department of Physics, University of Zambia P. 0. Box 32379, Lusaka, Zambia *Department of Applied Physics, Twenty University P. O. Box 217, 7500 AE Enschede, The Netherlands

Abstract High Gradient Magnetic Separation tests have been carried out on low grade refractory copper ores, consisting mainly of cupriferous micas. An effective concentration of copper was obtained for two types of ores. The copper grade was improved 2 and 1.5 times at a recovery of about $90 \%$. In particular, the amount of quartz in the concentrate could be reduced. This indicates that HGMS could be a successful method for concentration of these ores.

\title{
INTRODUCTION
}

During the mining of sulphide copper minerals from the Nchanga Open Pit in Zambia large amouns of low grade refractory ores were stockpiled separately. The mining industry is interested in developing suitable methods for the recovery of copper from the material which otherwise is considered as waste.

The refractory ores contain predominantly mica with some amounts of conventional copper minerals (mainly Malachite) and gangue material. Most of the copper is contained in the micas, with grades of $0.1-8.0 \%$. These micas are of an interstratified phlogopite-chlorite type in which the chlorite areas contain copper (1).

The extraction of copper from these micas is hampered by their slow leaching rate. The fact that they are weakly magnetic suggests that magnetic separation could be applied to concentrate the copper bearing material. Magnetic concentration of micaceous material was reported earlier by Schulze and Dixon (2). In particular the amount of quartz may be reduced, which will improve the 
effectivity of the leaching process. This was also indicated when leaching tests on micas concentrated by flotation appeared to be inferior to magnetically enriched micas ( 3 ). The aim of the work presented here is to investigate the possibility of upgrading the refractory ores by High Gradient Magnetic Separation.

\section{MAGNETIC SEPARATION}

Two types of refractory ores from the Nchanga Open Pit were studied; the Upper Banded Shale (UBS) and the Upper Banded Sandstone (BSSU), in sieved fractions of $38-53-75 \mu \mathrm{m}$ to minimize particle size effects.

In the samples a very small amount $(<0.1 \%)$ of strongly magnetic particles was present. Before applying HGMS the samples were screened on a Frantz L5 permanent magnet separator to remove these.

High Gradient Magnetic Separation was performed with a Frantz $\mathrm{CN}-1$, having an oblong canister with dimension $6 \times 25 \times 222 \mathrm{~mm}$ and volume $33 \mathrm{ml}$. The matrix material used was steelwool (S.G. Frantz Company, Inc.) of filament diameter 50-100um, occupying $2 \%$ of the filter volume. The average slurry flow velocity in the canister was $20 \mathrm{~mm} / \mathrm{s}$. The mechanically trapped particles were flushed out in the presence of the magnetic field with a flow velocity of about $200 \mathrm{~mm} / \mathrm{s}$. The magnetic particles were flushed out with the same velocity after switching off the field. The field $\mu . \mathrm{H}$ applied to the matrix was $1.3 \mathrm{~T}$. To prevent saturation of the filter the samples were split into batches of about $10 \mathrm{~g}$ of material in $400 \mathrm{ml}$ slurry which were treated successively.

\section{RESULTS}

The first test was done on a $53-75 \mu \mathrm{m}$ particle size fraction of Upper Banded Shale. To maximize the recovery of copper in the magnetic fractions the non-magnetic product was treated repeatedly. The resulting copper grades and recoveries in the different magnetic and the remaining non-magnetic products are given in Table $I$. The copper grades were determined by Atomic 
Absorption Spectrometry. In this Table, the magnetic susceptibilities of the fractions are also shown, these being measured with an electronic mutual inductance bridge.

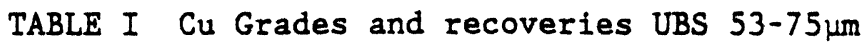

\begin{tabular}{lcccc}
\hline & weight \% & $\begin{array}{c}\mathrm{Cu} \\
\text { 8rade } \%\end{array}$ & $\begin{array}{c}\mathrm{Cu} \\
\text { recovery } \%\end{array}$ & $\begin{array}{c}\text { susceptibility } \\
\left(10^{-6} \mathrm{~m} / \mathrm{kg}\right)\end{array}$ \\
\hline mags & 15.2 & 1.75 & 33.7 & 0.143 \\
mags & 11.6 & 1.64 & 24.1 & 0.088 \\
mags & 9.3 & 1.41 & 16.6 & 0.070 \\
mags & 6.4 & 1.17 & 9.5 & 0.065 \\
nonmags & 57.5 & 0.22 & 16.0 & 0.007 \\
\hline feed & 100 & 0.79 & 100 & 0.047 \\
\hline
\end{tabular}

A recovery of $84 \%$ copper to the magnetic fractions with an upgrading of the copper content from $0.79 \%$ to $1.56 \%$ was obtained.

In addition to measuring the copper content, a microscopic analysis of the mineral distributions was performed in order to gain more information on the actual separation process. The material was therefore immersed in a liquid of refractive index $\mathrm{n}=1.55$ and inspected with transmitted light microscopy. In that way, micaceous material $(n=1.56)$ can readily be discriminated from quartz ( $n=1.54)$. Further colour and presence of inclusions were included in this analysis, so that four types of mica could be distinquished: coloured (yellow, green, brown), coloured plus major inclusion, colourless or pale, colourless plus major inclusion. Only the coloured micas contain copper (4). The inclusions consist of the iron minerals Hematite and Goethite (5).

From Table I it can be seen that the copper grade of the magnetic fractions reduces after repeated separations. This effect 
cannot be explained only by the increased recovery of quartz, which ranges from 21 to $36 \%$. Further, from the microscopic analysis it appears that the quartz particles contain inclusions which should give higher susceptibility. Apparently, the susceptibility of the micas drops with decreasing copper grade.

TABLE II Grade \% of minerals in UBS $53-75 \mu \mathrm{m}$

\begin{tabular}{lcccccc}
\hline & & $\begin{array}{c}\text { micas } \\
\text { colt }\end{array}$ & non & nont & quartz opaque \\
\hline mags 1 - 4 & 49 & 5.2 & 12 & 4.2 & 26 & 3.8 \\
nonmags & 13 & 0.7 & 12 & 3.6 & 70 & 1.3 \\
\hline feed (calc'd) & 28 & 2.6 & 12 & 3.8 & 52 & 2.2 \\
\hline
\end{tabular}

Table II shows the grades as obtained from the microscopic analysis. It appears that $74 \%$ of the coloured micas entered the magnetic fractions, as for the coloured micas with inclusions, this was 85\%. Higher recovery in the mags due to inclusions is expected considering the relatively high susceptibilities of the included material: $0.25 * 10^{-6} \mathrm{~m}^{3} / \mathrm{kg}$ and higher, compared to phlogopite $0.06 * 10^{-6} \mathrm{~m}^{3} / \mathrm{kg}$. This effect was not observed for the colourless micas with recovery percentages of respectively $43 \%$ and $46 \%$. Of the quartz $78 \%$ went into the non-magnetic fraction, which means that this material was effectively removed from the mica concentrate. Finally, $69 \%$ of the opague minerals was captured in the magnetic part.

The second test was performed on a $38-53 \mu \mathrm{m}$ particle size fraction of Upper Banded Shale. The results for the copper grades and recoveries are summarized in Table III. 
TABLE III $\mathrm{Cu}$ grades and recoveries UBS $38-53 \mu \mathrm{m}$

\begin{tabular}{lccc}
\hline & weight \% & $\begin{array}{c}\text { Cu } \\
\text { grade } \%\end{array}$ & $\begin{array}{c}\text { Cu } \\
\text { recovery \% }\end{array}$ \\
\hline mags & 39.7 & 1.96 & 91.5 \\
nonmags & 60.3 & 0.12 & 8.5 \\
\hline feed & 100 & 0.85 & 100 \\
\hline
\end{tabular}

This shows an even better result than for the bigger particles. From the microscopic analysis it is clear that this improvement is caused by the reduction of the amount of intergrowth of different minerals in the latter fraction.

Finally, HGMS was performed on a $38-75 \mu \mathrm{m}$ Upper Banded Sandstone sample. The results are shown in Tables IV and V.

TABLE IV Cu grades and recoveries BSSU $38-75 \mu \mathrm{m}$

\begin{tabular}{lccc}
\hline & weight $\%$ & $\begin{array}{c}\text { Cu } \\
\text { 8rade } \%\end{array}$ & $\begin{array}{c}\text { Cu } \\
\text { recovery \% }\end{array}$ \\
\hline mags & 60.4 & 4.1 & 91.6 \\
nonmags & 39.6 & 0.6 & 8.4 \\
\hline feed & 100 & 2.7 & 100 \\
\hline
\end{tabular}

Again, almost all of the copper present was recovered in the mags, now at a relatively high grade of $4.1 \%$. Compared to UBS here the average copper grade of the micas is higher, which favours the concentration process. 
TABLE V Grade \% of minerals in BSSU $38-75 \mu \mathrm{m}$

\begin{tabular}{lcrccccc}
\hline & & \multicolumn{2}{c}{ micas } & & quartz & opaque \\
& col & colt & non & nont & & \\
\hline mags & 51 & 20 & 13 & 8 & 5 & 5 \\
nonmags & 11 & 5 & 14 & 3 & 64 & 3 \\
\hline feed & 35 & 14 & 13 & 6 & 28 & 4 \\
\hline
\end{tabular}

For BSSU the recovery of the coloured micas with and without inclusions in the mags was $86 \%$ and $88 \%$ respectively. For the colourless micas these percentages were $80 \%$ and $59 \%$ Here the effect of inclusions was only observed in the colourless micas. The quartz was almost completely removed from the concentrated fraction: $90 \%$ in the non-mags. Of the opaque minerals $72 \%$ was captured in the magnetic part.

\section{CONCLUSION}

From these preliminary tests High Gradient Magnetic Separation looks to be a promising concentration method for cupriferous micas. The effect of decreasing copper grade with decreasing magnetic susceptibility may be used to set the process parameters for a lower limit of commercially extractable copper. Further tests are necessary to determine the optimum conditions for specific samples.

\section{ACKNOWLEDGEMENT}

The authors wish to thank the Zambian Mining Industrial Technical Service for the provision of samples. 


\section{REFERENCES}

[1] C.W. Notebaart, Trans. B. Inst. Min. Metall. 87 B74 (1978).

[2] D.G. Schulze and J.B. Dixon, Soil Sci. Am. J.43,793 (1979).

[3] MITS Internal Report, Project NMO1 (ex 3409).

[4] Private communication, Dr. R. Kuhnel, Delft.

[5] W.A. Basset, Am. Miner. 431112 (1958). 